Section Editor

John J. Millichap, MD

Jithin S. George, MRCP

John S. Elston,

FRCOphth

Correspondence to

Dr. Elston:

jelston@bch.nhs.uk
Mystery Case:

\section{Terson syndrome on CT head}

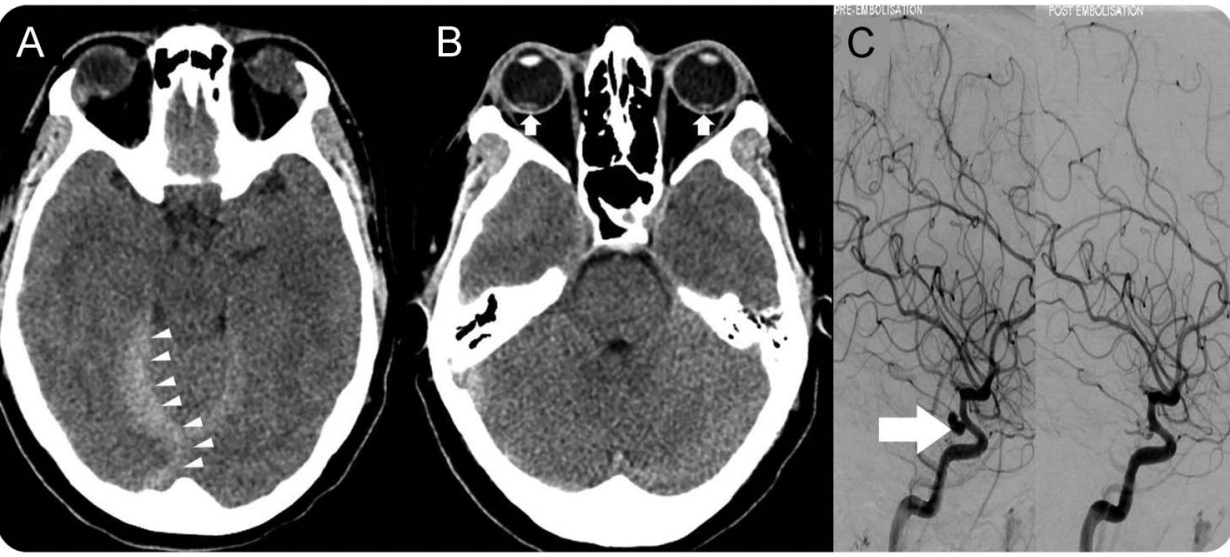

CT head demonstrates acute tentorial subdural hemorrhage (A, arrowheads) and crescentic hyperdensities consistent with intraocular blood (B, arrows). Cerebral angiogram before and after coil embolization of right posterior communicating artery aneurysm is shown (C, arrow).

A 36-year-old woman presented with acute severe headache and generalized tonic-clonic seizures. CT head scan revealed a tentorial acute subdural hemorrhage (ASDH) and posterior globe hyperdensities suggestive of intraocular blood with a right posterior communicating artery aneurysm on cerebral angiography (figure 1). Ophthalmologic assessment confirmed Terson syndrome (figure 2).

Terson's ${ }^{1}$ original definition of intravitreal hemorrhage (IVH) complicating subarachnoid hemorrhage has broadened to include ASDH with retinal and preretinal hemorrhages as well as IVH. ${ }^{2}$ Plain CT head can demonstrate Terson syndrome, which is easily missed and warrants ophthalmologic input. ${ }^{2}$ Significant persisting visual impairment may require vitrectomy with or without laser membranotomy.

\section{AUTHOR CONTRIBUTIONS}

Jithin S. George: conception and design of manuscript, acquisition, analysis, and interpretation of data, drafting/revising the manuscript for content, approved the final version. John S. Elston: conception and design of manuscript, analysis and interpretation of data, drafting/revising the manuscript for content, supervision, approved the final version.

\section{ACKNOWLEDGMENT}

The authors thank the patient for consenting to the publication of her case.

\section{STUDY FUNDING}

No funding was received for this study.

\section{DISCLOSURE}

The authors report no disclosures relevant to the manuscript. Go to Neurology.org for full disclosures.

\section{REFERENCES}

1. Terson A. De l'hémorrhagie dans le corps vitre au cours de l'hémorrhagie cerebrale. Clin Ophthalmol 1900;6:309-312.

2. Swallow CE, Tsuruda JS, Digre KB, et al. Terson syndrome: CT evaluation in 12 patients. AJNR Am J Neuroradiol 1998; 19:743-747.

\section{MYSTERY CASE RESPONSES}

The Mystery Case series was initiated by the Neurology ${ }^{\circledR}$ Resident \& Fellow Section to develop the clinical reasoning skills of trainees. Residency programs, medical student preceptors, and individuals were invited to use this Mystery Case as an educational tool. Responses were solicited through a group e-mail sent to the American Academy of Neurology Consortium of Neurology Residents and Fellows and through social media.

Of 18 respondents, 55\% correctly identified acute tentorial subdural hemorrhage on noncontrast

From the Nuffield Department of Clinical Neurosciences (J.S.G.); and Department of Ophthalmology (J.S.E.), Oxford Eye Hospital, John Radcliffe Hospital, Oxford, UK. Dr. George is currently affiliated with the Department of Neurology, University Hospitals Leicester NHS Trust, Leicester, UK. Dr. Elston is currently affiliated with the Birmingham Children's Hospital, Birmingham, UK. 


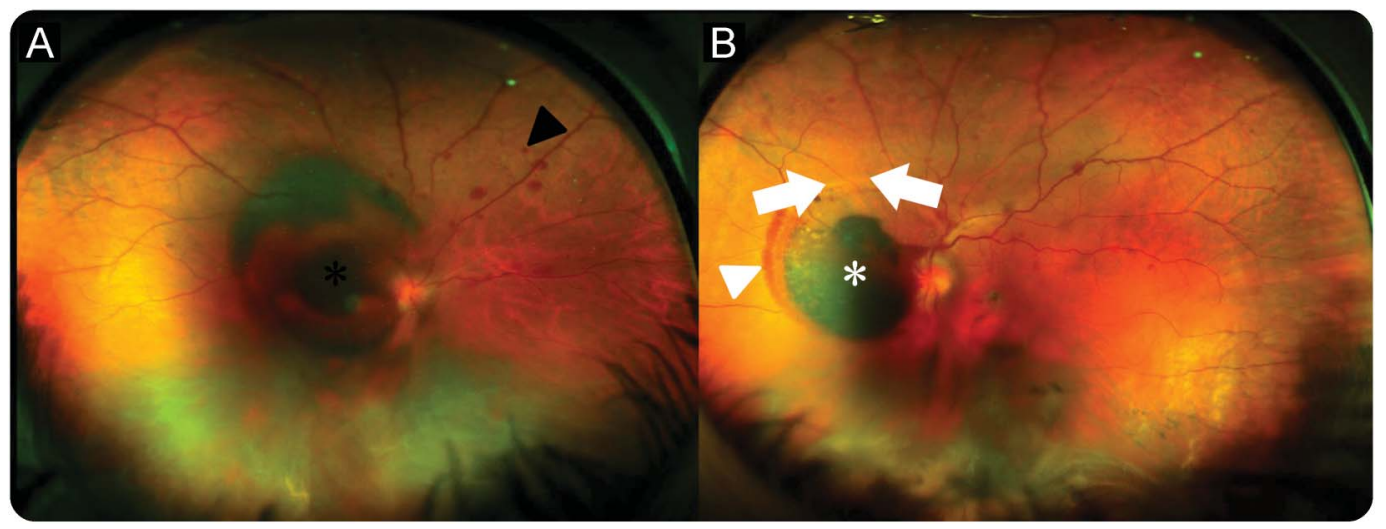

Wide-field scanning laser ophthalmoscopy (Optomap; Optos) using adaptive optics produces a digital fundus image by superimposing the 2 en face retinal raster scans from red and green wavelength lasers. The red laser light penetrates the retinal pigment epithelium up to the choroid, whereas green interrogates superficial retinal layers and retinal vessels. There is a large premacular hemorrhage $\mathrm{OD}$ ( $\mathrm{A}$, black asterisk). A smaller preretinal hemorrhage with a circular outline is present OS ( $B$, white asterisk); the inner limiting membrane (ILM) is visible as a glistening superior border ( $B$, between the 2 white arrows). In vivo optical coherence tomography scans or pathology specimens obtained following laser membranotomy can definitively identify whether the preretinal hemorrhages are sub-ILM or subhyaloid. Intravitreal extension accounts for the indistinct lower section of both fundus images (worse OD). Flame-shaped or arced, confluent retinal hemorrhages arising from the retinal nerve fiber layer are more superficial ( $B$, example of this next to white arrowhead), whereas a dot and blot pattern indicates hemorrhage within deeper retinal layers ( $A$, black arrowhead).

CT head scan, which also revealed bilateral posterior globe hyperdensities suggestive of intraocular blood. Thirty-eight percent said that there was an aneurysm seen on cerebral angiography, but only one respondent correctly identified it as a right posterior communicating artery aneurysm preembolization and postembolization. Wide-field laser ophthalmoscopy (Optomap; Optos, Dunfermline, UK) in figure 2 shows a large premacular hemorrhage of the right eye and smaller preretinal hemorrhage of the left eye. Combined, these findings are consistent with Terson syndrome, classically defined as intraocular hemorrhage associated with subarachnoid hemorrhage, the correct answer given by $44 \%$ of respondents. Terson syndrome is thought to be caused by a rapid spike in intracranial pressure and has also been reported in patients with intracerebral hemorrhage and traumatic brain injury.

This case illustrates the importance of considering intraocular hemorrhage in patients with acute rises in intracranial pressure and that in some cases the diagnosis can be aided by signs present on head CT.

Steve O'Donnell, MD

University of Utah, Salt Lake City 


\title{
Neurology
}

\author{
Mystery Case: Terson syndrome on CT head \\ Jithin S. George and John S. Elston \\ Neurology 2016;87; e133-e134 \\ DOI 10.1212/WNL.0000000000003143
}

This information is current as of September 26, 2016

\section{Updated Information \& Services}

\section{References}

Subspecialty Collections

Permissions \& Licensing

Reprints including high resolution figures, can be found at: http://n.neurology.org/content/87/13/e133.full

This article cites 2 articles, 0 of which you can access for free at: http://n.neurology.org/content/87/13/e133.full\#ref-list-1

This article, along with others on similar topics, appears in the following collection(s):

Intracerebral hemorrhage

http://n.neurology.org/cgi/collection/intracerebral_hemorrhage

Retina

http://n.neurology.org/cgi/collection/retina

Visual loss

http://n.neurology.org/cgi/collection/visual_loss

Information about reproducing this article in parts (figures,tables) or in its entirety can be found online at:

http://www.neurology.org/about/about_the_journal\#permissions

Information about ordering reprints can be found online:

http://n.neurology.org/subscribers/advertise

Neurology ${ }^{\circledR}$ is the official journal of the American Academy of Neurology. Published continuously since 1951, it is now a weekly with 48 issues per year. Copyright @ 2016 American Academy of Neurology. All rights reserved. Print ISSN: 0028-3878. Online ISSN: 1526-632X.

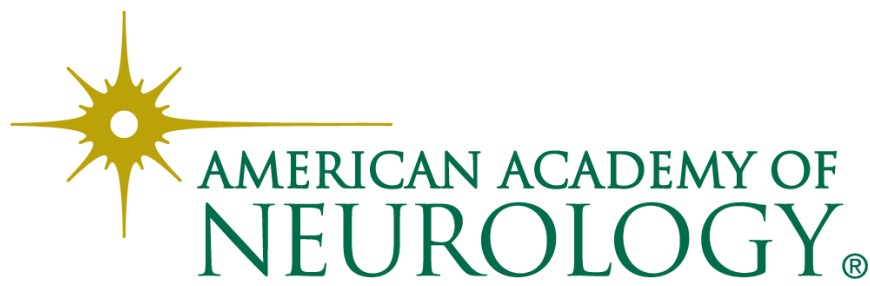

